\title{
2006-2286: EMPIRICALLY DERIVED DESIGN PRINCIPLES FOR ENGINEERING EDUCATOR RESOURCES
}

\section{Matt Eliot, University of Washington}

Matt Eliot is a doctoral candidate in the Technical Communication department of the University of Washington. His interests include product design, the structure of meaningful product experiences, and human-centered design. He can be reached at mjeliot@u.washington.edu.

\section{Roxane Neal, University of Washington}

Roxane Neal is a usability engineer and web site designer leading the development of the NEXT web site. She earned her Master's degree in Technical Communication from the University of Washington in December 2005. She can be reached at roxanen@u.washington.edu.

\section{Jennifer Turns, University of Washington}

Dr. Jennifer Turns is faculty in the College of Engineering at the University of Washington. Her research interests include engineering education, user-centered design, information design, audience analysis, and the role of technology in learning. Dr. Turns uses a variety of methods for this research including verbal protocol analysis, concept mapping, and ethnography. She earned her Ph.D. from the Georgia Institute of Technology. She can be reached at jturns@u.washington.edu. 


\section{Empirically Derived Design Principles for Engineering Educator Resources}

\section{Introduction}

As a discipline, engineering education is in a time of great innovation. Committed to teaching excellence, educators and researchers have explored issues specific to engineering education and have developed a number of relevant resources. These resources include teaching workshops, one-on-one instructional consultations, online resources, and engineering-specific course materials. In the face of this resource explosion, however, one can wonder about the degree to which some of these products are effective and useful to their intended users. The use of design principles drawn from empirical research with engineering faculty can provide a powerful adjunct to resource design, increasing the potential for relevance, usability, and satisfaction.

User experience researchers investigate the needs and goals of a product's target audience with the intention of gathering useful information to guide the design process. There are a number of methods by which these researchers frame their findings for designers, including heuristics ${ }^{1}$, patterns $^{2}$, and principles ${ }^{3}$. Design heuristics focus on common issues that users have with a particular type of product and how those issues should be approached. Design patterns often focus on standardized solutions to common problems.

Design principles, on the other hand, are guidelines that address issues surrounding content, form, and interaction behavior. Such principles can be derived from a number of sources: empirical research of the target user group, the designer's knowledge of the design context, previously published information about the context, and administrative policy. Design principles differ slightly from heuristics and patterns as they are more generalizable and applied to multiple genres of resources.

In this paper, we will first describe an initial set of principles for designing engineering education resources and the data-driven rationale for creating them. We will then present the initial page designs for our current prototype web site for engineering faculty, explaining how these designs instantiate our design principles. The current prototype can be found at http://depts.washington.edu/next.

We will also impart the results of our first round of expert evaluation and the relationship between these experts' feedback and our design principles. We offer the details of our website and the results of our evaluation in order to further explicate the design principles; as a result we will not focus on possible alternative web site designs. The following section describes the empirical research from these design principles were derived. 


\section{Where these principles came from}

This research is based on an NSF-sponsored study (EEP-0211774) of engineering faculty at a Research Extensive institution which had two explicit goals: (1) the development of a "thick description" of teaching challenges faced by engineering educators and (2) the testing of our findings through the creation of a resource web site specifically for engineering educators ${ }^{4}$. We developed our set of design principles during our general data analysis process and the early stages of our web site design process.

To fulfill the first goal of this study, a thick description of engineering educator's teaching challenges, we debriefed an instructional consultant after consultations with individual engineering faculty and teaching-related groups. In all, we held 66 debriefing interviews, which were analyzed via qualitative coding methods to reveal 366 unique teaching concerns 5 . These concerns were in turn aggregated into 17 themes, which served as a "rich description" of key opportunities for the advancement of engineering education. Through this process, we gained important insights into the complexities and cultural issues that limit engineering faculty's teaching performance and teaching satisfaction and more broadly their job performance and their job satisfaction.

The second goal of this study was the creation of a web site specifically for engineering educators that would provide assistance for their common teaching challenges. In our data analysis process, we discovered that the engineering faculty who participated in this study rarely came to the instructional consultation process with simple problems to be solved. Instead, these faculty brought complex and difficult situations which ranged from junior faculty concerned about the impact of active learning techniques on their student ratings to more experienced faculty needing help writing the education section of the NSF's Broader Impacts criteria for a grant proposal. This basic observation about the complexity of engineering educators' teaching challenges spurred this research group to generate an empirically-grounded set of design principles for this population.

\section{Design principles for engineering educator resources}

The following is a list of our design principles as well as the empirical basis for each principle synthesized from findings from our analysis of the interview transcripts. These design principles could be used by engineering educators, especially those new to the field, as criteria for evaluating teaching-related resources.

Design Principle \#1: A resource for engineering educators should help them break down complex teaching situations into smaller, more manageable elements.

Empirical basis: Engineering educators often came to the instructional consultation process with complex teaching situations. In this study, the instructional consultant analyzed these complex teaching situations, broke them down into manageable elements, and assisted educators in finding specific and concrete solutions. Engineering educators may benefit from support for these vital skills. 
Design Principle \#2: A resource for engineering educators should help them connect to the broader educational context (education terminology and research).

Empirical basis: A number of educators in this study had difficulties with education terminology and education research. The instructional consultant helped these clients find the right label (e.g., problem-based learning) for their needs and goals, and then connected these educators with the appropriate resources. Consequently, when looking for resources on their own, some educators may lack the conceptual understanding and the appropriate language to find these resources and to engage them effectively.

Design Principle \#3: A resource for engineering educators should help them understand the purposes and benefits of mentorship, particularly instructional consultation.

Empirical basis: The instructional consultant actively helped her clients to build professional networks with such people as department chairs, peers, funding agency officers, and more experienced colleagues. Such networks may provide opportunities for mentorship on professional issues. In addition, she also educated her clients about the many services she provided as part of the instructional consultation process. Engineering educators may benefit from an increased understanding of the many kinds of support that are available to them.

Design Principle \#4: A resource for engineering educators should help them to see their engineering discipline represented in resource materials.

Empirical basis: A number of educators in this study were concerned whether generic teaching resources would be relevant or useful to their specific teaching situation, especially in terms of their discipline. A concerned was expressed, for example, as to whether an active-learning approach developed for chemistry would be relevant to the engineering classroom. Designers wanting to increase engineering educators engagement with their materials may want to frame their products specifically for their intended audience.

Design Principle \#5: A resource for engineering educators should help them to see themselves represented in resource materials.

Empirical basis: In our study, a variety of groups expressed difficulty seeing themselves in the engineering education community, whether pertaining to junior educators, experienced educators, female educators, international educators, or educators of color.

Design Principle \#6: Engineering educators need a class of materials that help them connect with mainstream teaching resources.

Empirical basis: The instructional consultant in this study spent an appreciable amount of time helping engineering educators make use of existing resources through describing the overall context, explaining specific educational terminology, and explaining her own criteria for selecting resources. Engineering educators need assistance when engaging mainstream resources. 
Design Principle \#7: Engineering education resources should be accessible to a variety of gatekeepers beyond classroom instructors.

Empirical basis: The instructional consultant in this study acted as a gatekeeper, filtering through huge numbers of educational materials and selecting only those that were accessible and pertinent to her clients' needs. Other gatekeepers serving the engineering education community include department chairs, teaching and learning centers, and professional organizations. While the people in these various roles may not mentor faculty directly, designers may want to make their materials accessible to these gatekeepers as well.

This set of principles seems generic enough to be applied during the design of a variety of resources for engineering educators. In the following section, we describe one instantiation of these principles - our prototype web site for engineering educators.

\section{From principles to prototype}

The second goal of this study was the creation of a web site resource for engineering educators. We began the actual design of this web site with a review of currently existing sites, both those for engineering educators and those for a more general audience. After reviewing a number of such web sites, we chose a journalistic story approach for our prototype design. This approach allowed us to instantiate our design principles while achieving our main goals: replicating key benefits of the instructional consultation process while connecting our users to a number of excellent resources already existing on the Web.

The story format offers a number of important affordances in any work-related community. Stories are a primary means of sharing previously tacit knowledge, especially related to the diagnosis of problems and the preservation of solution-based knowledge. Writing from a Communities of Practice perspective, Brown and Duguid ${ }^{6}$ suggest that stories serve as "repositories of accumulated wisdom," and the sharing of stories among workers is integral to knowledge- and skill-building. Hildreth et al. ${ }^{7}$ link stories to workers' transitions "from newcomer to old-timer," with stories communicating shared understanding while increasing expertise.

To take advantage of the powerful potentials of story-telling, we designed our stories as follows. First, a protagonist is faced with a complex teaching situation for which they have no ready solution. Second, the protagonist then seeks help from a mentor, who breaks the situation down into its key elements. Third, these key elements, or strategies, are then described in terms that readers of the web site will understand and are accompanied by annotated links to relevant online resources. We named our site to capture this central use of stories, "NEXT: Narratives supporting Excellent Teaching."

The following figures offer a comprehensive view of our story pages. Figure 1 illustrates our working blueprint for the story pages. Figure 2 is an actual screen shot of a prototype story page. Following these figures, each design element on a story page is described in greater detail, including their links with the design principles. 


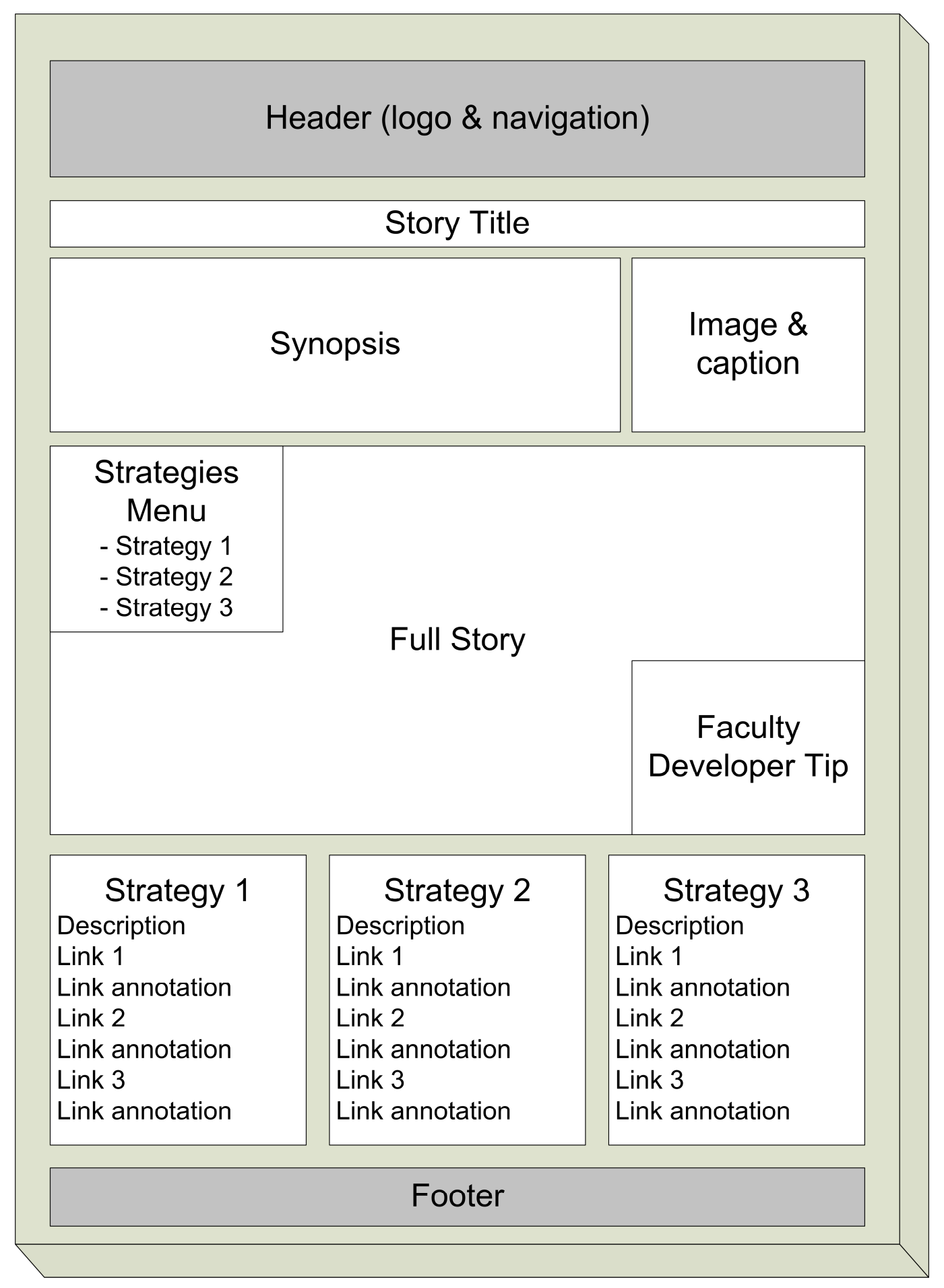

Figure 1. Design elements on a NEXT story page. 




Figure 2. A screen shot of the current version of one of the story pages on our prototype site, as of January 13, 2006. 
The development of our design principles occurred during both primary data analysis and the early stages of our web design process. They were invaluable in our process of creating specific design features that would assist readers of the web site to quickly grasp the essentials of each story and gain useful context for the linked resources. The following list of page design elements includes a description of their connection to our design principles:

Synopsis. These are similar to the opening paragraph of a newspaper article. The synopsis gives a summary of the complex teaching situation for someone quickly scanning the page before reading further. This is also our readers' first opportunity to identify with the narrative-finding a problem like their own.

Related design principle:

- A resource for engineering educators should help them to see themselves represented in resource materials. (Design Principle \#5)

Full story. The protagonist is given a number of details that help readers of the web site increase their sense of identification and inclusion: specific engineering discipline, level of experience, and some demographic details. The complexities of the problematic teaching situation are also explained, helping the readers map the situation in the narrative to a similar one of their own. Each story also portrays a mentoring relationship, where the faculty member receives advice from someone with more experience in the relevant situation, e.g, more experienced colleagues, a department chair, or an instructional consultant. The variety of such relationships portrayed throughout the site may inspire faculty to seek out mentoring in new ways. The narrative concludes with the mentor delineating three or more strategies for rectifying the problem situation and increasing professional skills.

Related design principles:

- A resource for engineering educators should help them break down complex teaching situations into smaller, more manageable elements. (Design Principle \#1)

- A resource for engineering educators should help them understand the purposes and benefits of mentorship, particularly instructional consultation. (Design Principle \#3)

- A resource for engineering educators should help them to see their engineering discipline represented in resource materials. (Design Principle \#4)

- A resource for engineering educators should help them to see themselves represented in resource materials. (Design Principle \#5)

Picture and caption. These elements add visual interest to the page while helping readers see themselves represented in the site.

Related design principle:

- A resource for engineering educators should help them to see themselves represented in resource materials. (Design Principle \#5) 
Strategies menu. This menu alerts the reader to content at the bottom of the page while also emphasizing the central function of the narrative: breaking down complex teaching situations into manageable solutions.

Related design principle:

- A resource for engineering educators should help them break down complex teaching situations into smaller, more manageable elements. (Design Principle \#1)

Faculty developer tips. This feature serves two functions. First, it is a primary take-away from the page, an idea that is central to the resolution of the problem teaching situation. Second, like the mentoring relationship in the narrative, this feature models the type of support that is available from an instructional consultant.

Related design principles:

- A resource for engineering educators should help them break down complex teaching situations into smaller, more manageable elements. (Design Principle \#1)

- A resource for engineering educators should help them understand the purposes and benefits of mentorship, particularly instructional consultation. (Design Principle \#3)

Strategy descriptions. These short paragraphs provide suggestions on how to use the associated links and explain key education terminology. Sometimes these explanations are a short pithy phrase or a full sentence in length.

Related design principles:

- A resource for engineering educators should help them break down complex teaching situations into smaller, more manageable elements. (Design Principle \#1)

- A resource for engineering educators should help them connect to the broader educational context (education terminology and research). (Design Principle \#2)

- Engineering educators need a class of resources that help them connect with mainstream teaching materials. (Design Principle \#6)

Link annotations. Similar to the strategy descriptions, these texts describe how the associated resources (web sites, pdf documents, etc.) are useful to the problem situation.

Related design principles:

- A resource for engineering educators should help them break down complex teaching situations into smaller, more manageable elements. (Design Principle \#1)

- A resource for engineering educators should help them connect to the broader educational context (education terminology and research). (Design Principle \#2)

- Engineering educators need a class of resources that help them connect with mainstream teaching materials. (Design Principle \#6)

The final principle in our set of design principles was not linked to any story page feature, but guided the development of the site in general: Engineering education resources should be accessible to a variety of gatekeepers beyond classroom instructors (Design Principle \#7). It was clear from our research that there are a number of people who help engineering faculty work 
with available resources, including instructional consultants, colleagues, department chairs, etc. We referred to this principle when creating the content for the pages, wanting to make sure that our site was accessible to those gatekeepers beyond teaching faculty.

The initial prototype of the NEXT web site went live in mid-December 2005. Its current URL is http://depts.washington.edu/next/. After having developed a working prototype, we turned to a group of external advisors for feedback on our site design and content. The following section describes the results of this process.

\section{Results of January 2006 evaluation}

In any product design project, it is imperative to receive quality feedback from the target audience. Such feedback can help guide the product refinement process, leading to resources that are valuable and effective to their users. In December 2005, we completed a working prototype of five story pages, a home page, a story index page, a keyword index page, and an "About Us" page. To gain needed feedback, we invited eight engineering education experts - four instructional consultants and four researchers in the engineering education discipline - to review the site and offer feedback on three areas: (1) the general concept for the site, specifically the use of stories; (2) the credibility and the accuracy of the narratives themselves; and (3) the selection of links offered for each strategy. These expert evaluators explored the prototype site, read the story pages, and followed links to the external resources. They all provided their reactions via email, many offering multiple pages of helpful comments.

Given these experts' comments, the use of our design principles has proven to be both relevant and useful. As of mid-January 2006, we have reviewed feedback from most of our evaluators. In general, these evaluators thought our prototype is a great foundation needing some minor tweaking. We received a very positive reaction to our stories and design elements as well as received important suggestions. Below are four examples of feedback that either demonstrate the success of using these design principles or reinforce the importance of the principles in building effective resources for engineering educators.

Stories work. In response to our question about the utility of the story format, all of our evaluators agreed that the concept was beneficial. They reported that our stories were engaging and would effectively help readers of our site: engineering educators in need of teaching related solutions. Each of these experts was confident that the story approach would be effective in engaging our intended audience, helping them to identify with the protagonist and the problem situation, and guiding them to useful solutions and online resources. In the face of such positive feedback, there was also a concern about whether more detail was needed to help the readers of the web site identify with the protagonist in the story. One of the evaluators, an instructional consultant, summed up this concern with the following quote:

"I think [the use of stories is] a good idea, but I expect that the more people can identify with the characters or issues in the stories, the more useful the stories will be for drawing people into the case and exploring the strategies and resources. Because of that, I think it might help to expand the stories slightly." 
Related design principle supported by this feedback:

- A resource for engineering educators should help them to see themselves represented in resource materials. (Design Principle \#5)

Keep it engineering-specific. We also received some feedback related to the degree to which the web site was tailored to an engineering audience. Multiple evaluators advised us to ensure that our linked resources are engineering-specific. Our evaluators pointed out that some of our external resources, despite our efforts to find engineering- and science-focused materials, addressed a broad audience (including humanities educators) and contained examples and terminology that may turn off our engineering audience.

Related design principle reinforced by this feedback:

- A resource for engineering educators should help them to see their engineering discipline represented in resource materials. (Design Principle \#4)

Remind them to make changes slowly. Multiple evaluators also suggested that our web site should advise engineering educators (the readers of this web site) to initially make small and incremental changes to their teaching. The site should also remind them that trying new techniques could be bumpy. Our experts were concerned that readers of our site would be overwhelmed by taking on too many or too significant of changes. This finding had an important impact on our design principles, suggesting the possible addition of a new one: $A$ resource for engineering faculty should realistically portray the time and effort involved when adopting new teaching methods.

Related design principle reinforced by this feedback:

- A resource for engineering educators should help them break down complex teaching situations into smaller, more manageable elements. (Design Principle \#1)

Make it realistic. Another recurring comment from our evaluators is that the stories were not as realistic of actual faculty experience as these experts have witnessed. For example, one evaluator commented that the portrayal of students in a story called "My Students Look Bored in Class" was more positive than the way that actual faculty have described such student behavior to this evaluator.

Related design principle reinforced by this feedback:

- A resource for engineering educators should help them to see themselves represented in resource materials. (Design Principle \#5)

This expert evaluation demonstrated that we have an effective prototype and that the elements used in our web site support our design principles. The evaluation provided a wealth of suggestions that help an engineering faculty audience better identify themselves in the stories, provide more relevant advice from the mentor or our strategies, and provide more appropriate external resources. We are on track to delivering a site that can engage engineering faculty faced with a teaching dilemma and that can guide them to resources. The evaluator's comments pointed out avenues for improving our web site while reinforcing the legitimacy and value of the seven design principles we have developed. 


\section{Conclusion}

In this paper we have described our working set of design principles for engineering educator resources, how they were developed, and how they were applied to the design of a specific resource. Our immediate next step is further refinement of our NEXT web site. This will include further testing with our targeted user group and the development of more stories. These activities will, in turn, help us further polish this set of design principles.

The design principles presented in this paper may have wider applicability than the creation of a particular web-based resource. We believe that they could be usefully applied during the development of resources for issues ranging from departmental teaching policies to curriculum design. Our hope is that the explication of these design principles inspires resource developers to employ these principles to increase the perceived relevance and accessibility of teaching-related resources to engineering educators.

\section{Acknowledgements}

We would like to thank the following parties for their support over the course of this project: the National Science Foundation (EEP-0211774) for funding this project; Angela Linse, Cynthia Atman, and Robin Adams for serving as Co-Principal Investigators for this study; Richard Felder, Rebecca Brent, Susan Ambrose, Wayne Jacobsen, and Jim Borgford-Parnell for serving as external advisors; and Steve Lappenbusch, YiMin Huang, Zhiwei Guan, and Jessica Yellin for serving as internal advisors as part of the Laboratory for User-Centered Engineering Education at the University of Washington.

We would also like to thank the many people who developed the web sites, articles, research, guides, and other teaching-related resources that we have linked to on our web site. Our site could not exist without their expertise and hard work.

\section{References}

1. De Jong, M. and Van Der Geest, T. (2000). Characterizing web heuristics. Technical Communication, 47(3), pp. 311-326.

2. Van Duyn, D.K., Landay, J.A., and Hong, J.I. (2003). Making the most of web design patterns. In The Design of Sites: Patterns, principles, and process for crafting a customer-centered web experience. Addison-Wesley: Boston, pp. 19-29.

3. Cooper, A. (2003). About Face 2.0: The Essentials of Interaction Design. Indianapolis, IN: Wiley Publishing, Inc.

4. Turns, J., Eliot, M., \& Linse, A. (2003, June). Exploring the teaching challenges of engineering faculty: What do they really want to know? Paper presented at the 2003 ASEE Annual Conference \& Exposition, Nashville, TN. 
5. Eliot, M., Neal, R., \& Turns, J. (2005, July). Recognizing need: The analysis of qualitative data to inform web site design. Paper presented at the 2005 International Professional Communication Conference (IPCC 2005), Limerick, Ireland.

6. Brown, J. S., and P. Duguid. (1991). Organizational learning and communities of practice: Toward a unified view of working, learning and innovation. Organizational Science, (2), pp. 40-57.

7. Hildreth, P., Kimble, C., and Wright, P. (2000). Communities of practice in the distributed international environment. Journal of Knowledge Management, 4(1), pp. 27-38. 